\title{
Supercritical Fluid Extraction of Berry Seeds: Chemical Composition and Antioxidant Activity
}

\author{
Graziele Gustinelli (D), ${ }^{1,2}$ Lovisa Eliasson, ${ }^{1}$ Cecilia Svelander, ${ }^{2}$ Thomas Andlid, ${ }^{2}$ \\ Leif Lundin, ${ }^{1}$ Lilia Ahrné, ${ }^{1,2,3}$ and Marie Alminger ${ }^{2}$ \\ ${ }^{1}$ Department of Bioscience and Materials, Research Institutes of Sweden, Gothenburg 402 29, Sweden \\ ${ }^{2}$ Department of Biology and Biological Engineering, Chalmers University of Technology, Gothenburg 412 96, Sweden \\ ${ }^{3}$ Department of Food Science, Ingredient and Dairy Technology, University of Copenhagen, Copenhagen 1958, Denmark
}

Correspondence should be addressed to Graziele Gustinelli; graziele.gustinelli@ri.se

Received 9 April 2018; Revised 3 July 2018; Accepted 5 August 2018; Published 17 September 2018

Academic Editor: Blaž Cigić

Copyright (c) 2018 Graziele Gustinelli et al. This is an open access article distributed under the Creative Commons Attribution License, which permits unrestricted use, distribution, and reproduction in any medium, provided the original work is properly cited.

\begin{abstract}
The influence of supercritical fluid extraction (SFE) and solvent extraction of oils from cloudberry, bilberry, and black currant seeds on the yield, chemical properties, and recovery of antioxidant compounds was investigated. SFE was performed for $1 \mathrm{~h}$ at 350 bar and at $50^{\circ} \mathrm{C}$ and $80^{\circ} \mathrm{C}$. Fatty acids, vitamin E, carotenoids, and free radical-scavenging activity (DPPH) were assayed. SFE at $80^{\circ} \mathrm{C}$ resulted in higher oil yields for cloudberry and black currant seeds. The oils were rich in polyunsaturated fatty acids (PUFAs) $(66.8 \%-75.9 \% \mathrm{w} / \mathrm{w})$, with high percentages of linoleic and $\alpha$-linolenic acids. The black currant seed extracts had the highest concentrations of vitamin E (range, $113.0-241.8 \mathrm{mg} / 100 \mathrm{~g}$ oil) and carotenoids (range, $11.5-32.3 \mathrm{mg} / 100 \mathrm{~g}$ oil) and the highest antioxidant activity. The cloudberry seed oils also had high antioxidant content and activity. These findings indicate the potential of SFE for the recovery of PUFA and antioxidant compounds in berry by-products.
\end{abstract}

\section{Introduction}

Berries are a common raw material that is processed in the food and juice industry. However, the processing of berries generates large amounts of solid by-products in the forms of peel, pulp, and seeds, which are mostly under utilised [1]. The wastes are usually burnt or deposited in landfills and hence, cause significant impact on the environment [2]. An alternative approach that reduces the amount of waste produced and promotes socioeconomic and environmental benefits is the valorisation of by-products through the extraction of valuable compounds [3].

Berry seeds are rich in oil, and their utilisation offers several advantages as their lipids generally have a high content of polyunsaturated fatty acids (PUFAs) and a favourable $n-6 / n-3$ ratio compared to other vegetable oils $[4,5]$. In addition, these oils are rich in vitamin E, carotenoids, and bioactive compounds with antioxidant activities [5].
Supercritical fluid extraction (SFE) is a green method for the extraction of valuable compounds from berry seeds, in contrast to conventional extraction methods that use hazardous organic solvents. The advantages of working with SFE are reduced solvent use, shorter extraction time, and lower energy consumption, as compared with the conventional extraction methods, such as solvent extraction and cold-pressing. SFE also allows the fractionation of compounds by adjusting the pressure and temperature based on the solubilities of the targeted compounds [6]. Moreover, the solvent is easily separated from the extract by depressurisation of the supercritical fluid, thereby saving time, and the fact that organic solvents are not used makes the extract suitable for use in the food industry [7]. The selectivity of SFE for the extraction of target compounds has previously been reported for the extraction of antioxidants in oil from grape seeds $[3,8]$ and vitamin $\mathrm{E}$ and carotenoids from other berries $[4,9]$. However, there is little information available 
regarding the recovery using SFE of antioxidants from berry seeds.

The plant matrix is an important parameter for extraction [7]. Matrix pretreatments, such as milling, can increase the extraction efficiency by breaking the cells, thereby increasing the surface area for mass transfer [10]. The oil at the surface and in the shallow subsurface is quickly extracted, whereas the oil inside the intact cells, in the particle core, has stronger mass transfer resistance [11]. A better understanding of how the different kinds of berry matrices and cell structure morphologies are affected by milling is essential to improve the extraction efficiency.

The objective of this study was to investigate the yields, chemical compositions, and recovery of antioxidant compounds of SFE-extracted oils from the seeds of cloudberries, black currants, and bilberries. The oils were extracted by SFE at different temperatures $\left(50^{\circ} \mathrm{C}\right.$ and $\left.80^{\circ} \mathrm{C}\right)$ and compared with oils that were obtained from the same seeds using conventional solvent extraction with hexane. In addition, the microstructures of seed particles were visualised using light microscopy to elucidate the influence of cell morphology on the extraction efficacy.

\section{Materials and Methods}

2.1. Chemicals. Carbon dioxide ( $>99.99 \%)$ was purchased from AGA Gas AB (Växjö, Sweden). The internal standard heptanoic (margaric) acid 17:0 $(\geq 99 \%)$ and the external standards of FAME mixture GLC 463 and stearidonic acid $18: 4 \mathrm{n}-3$ were purchased from Nu-Chek Prep Inc. (Elysian, USA). DL $\alpha$-tocopherol ( $\geq 97 \%)$ and 1,1-diphenyl-2picrylhydrazyl (DPPH) were obtained from Alfa Aesar $\mathrm{GmbH}$ (Karlsruhe, Germany). The standards $\delta$-tocopherol (95.5\%) and $\gamma$-tocopherol (97.3\%) were from Supelco (Bellefonte, PA, USA), and $\alpha$-tocotrienol (97\%), $(R)$ $\gamma$-tocotrienol $(\geq 97.0 \%)$, and acetyl chloride $(\geq 99.0 \%)$ were obtained from Fluka, Sigma-Aldrich (Stockholm, Sweden). Methanol (LC-MS grade $\geq 99.9 \%$ ), toluene (HPLC grade 99.9\%), cyclohexane (HPLC grade $\geq 99.7 \%$ ), petroleum ether (ACS reagent, $\geq 95.0 \%$ ), tert-butyl methyl ether (MTBE) (HPLC grade $\geq 99.8 \%$ ), and Tween 80 were all from SigmaAldrich (Stockholm, Sweden). 2,2,4-Trimethylpentane (HPLC grade 99.5\%) was purchased from Labscan (Dublin, Ireland). Ethanol absolute (AnalaR NORMAPUR) was from VWR International (Spånga, Sweden).

2.2. Berry Seeds. The berries were picked in Norrbotten, northern Sweden. Cloudberries (Rubus chamaemorus) and bilberries (Vaccinium myrtillus L.) were grown wild, and the black currants (Ribes nigrum L.) were cultivated. The seeds were separated from the press cake (obtained after juice removal) in a pureeing machine (Robot Coupe C200) and stored at $-40^{\circ} \mathrm{C}$. The seeds were thawed at $4^{\circ} \mathrm{C}$ and dried in a hot-air oven at $40^{\circ} \mathrm{C}$ (Garomat 142; Electrolux $\mathrm{AB}$, Stockholm, Sweden) until a moisture content of approximately $6.5 \%$ was obtained. After drying, the seeds were kept in the freezer at $-40^{\circ} \mathrm{C}$ until use in the extraction experiments. Immediately before extraction, the seeds were ground for $30 \mathrm{~s}$ in a coffee mill (model 2393; OBH Nordica, Stockholm, Sweden).

2.3. Solvent Extraction. The extractions were performed with a mixture of $1 \mathrm{~g}$ of milled seeds and $10 \mathrm{~mL}$ of hexane. The mixtures were mixed for $2 \mathrm{~h}$ in an orbital rotary plate (Reax2; Heidolph GmbH, Schwabach, Germany) at $150 \mathrm{rpm}$. After shaking, the mixtures were centrifuged in a Heraeus-Kendro Multifuge 1S (Heraeus GmbH, Hanau, Germany) for $10 \mathrm{~min}$ $(3000 \times g)$. The supernatants were collected, and the procedure was repeated. The supernatants were pooled, and the solvent was evaporated by flushing the samples with $\mathrm{N}_{2}$ at $40^{\circ} \mathrm{C}$. The evaporated extracts were stored at $-18^{\circ} \mathrm{C}$ until the analysis. The extractions were performed in 18 replicates for bilberry seeds and 30 replicates for cloudberry and black currant seeds. A high amount of extractions were carried out to ensure that there was sufficient oil for the analysis.

2.4. Supercritical Fluid Extraction (SFE) of Berry Seeds. The supercritical fluid extractions were carried out in triplicate, using a laboratory-scale supercritical fluid system (SFE-500M1-2-C50; Waters Corp., Milford, MA, USA). The unit consisted of a $\mathrm{CO}_{2}$ pump connected to a cooling bath (F32-HD; Julabo GmbH, Seelbach, Germany), an automated back-pressure regulator, a cylindrical extractor vessel of volume $500 \mathrm{~mL}$ equipped with a heating jacket, and one separation vessel $(500 \mathrm{~mL})$ kept at 10 bar and $25^{\circ} \mathrm{C}$. Ground seeds $(50 \pm 0.5 \mathrm{~g})$ were loaded into the extraction vessel. For each extraction, $2 \mathrm{~g}$ of glass wool was used to protect the vessel filters and to fill up the empty space of the vessel. The extractions were carried out for $60 \mathrm{~min}$ at a flow rate of $30 \mathrm{~g}$ $\mathrm{CO}_{2} / \mathrm{min}$. The extraction pressure was $350 \mathrm{bar}$, and the extraction temperature was $50^{\circ} \mathrm{C}$ or $80^{\circ} \mathrm{C}$. The extracts obtained after SFE were used for estimation of fatty acids, tocopherols, tocotrienols, carotenoids, and DPPH. Due to the small volumes obtained from each extraction, the triplicates were pooled; hence, this limited the interpretation of the results. The extracts were stored at $-18^{\circ} \mathrm{C}$ until the analysis.

2.5. Light Microscopy (LM) Analysis. The milled seeds were smeared on the surface of a microscope slide, and a droplet of water was added to disperse the fragments of seeds. The microstructures of the berry seeds were examined under a Microphot FXA microscope (Nikon, Tokyo, Japan). Images were acquired with an Altra 20 camera (Olympus, Tokyo, Japan), and the objective lenses $\times 10$ and $\times 20$ were used.

2.6. Fatty Acid Analysis by Gas Chromatography (GC). The methylation of fatty acids from bilberry, black currant, and cloudberry seed oils was based on the method of Cavonius et al. [12]. Toluene $(1 \mathrm{~mL})$ was added to the extracts $(0.025 \pm 0.005 \mathrm{~g})$ and then mixed with $1 \mathrm{~mL}$ of freshly prepared 10\% (v/v) acetyl chloride in methanol. The solutions were incubated for $2 \mathrm{~h}$ at $70^{\circ} \mathrm{C}$. After cooling to room temperature, $1 \mathrm{~mL}$ of Milli- $\mathrm{Q}$ water was added, followed by 
$2 \mathrm{~mL}$ of petroleum ether. The solutions were vortexed and centrifuged for $5 \mathrm{~min}$ at $2500 \times \mathrm{g}$. The supernatant that contained the methyl esters of fatty acids (FAMEs) was collected in a new tube, evaporated under $\mathrm{N}_{2}$ at $40^{\circ} \mathrm{C}$, and redissolved in $1 \mathrm{~mL}$ of 2,2,4-trimethylpentane. The samples were analysed by using a GC (7890 A; Agilent Technologies, Santa Clara, CA, USA) with a triple-axis mass spectrometric (MS) detector in the electron impact mode (5975 C; Agilent Technologies) and equipped with a J\&W DB-wax column $(30 \mathrm{~m} \times 0.250 \mathrm{~mm} \times 0.25 \mu \mathrm{m})$. Helium was used as the carrier gas. External standards were used for the identification of the peaks, and an internal standard $(17: 0)$ was used for the quantification of fatty acids. The limit of detection was $50 \mu \mathrm{g} / \mathrm{mL}$ for $17: 0$. The results were calculated in grams of FA per $100 \mathrm{~g}$ of oil.

2.7. Determination of Tocopherols and Tocotrienols by HighPerformance Liquid Chromatography (HPLC). Methanol $(2 \mathrm{~mL})$ was added to $0.04 \pm 0.005 \mathrm{~g}$ of extracts and vortexed. The samples were sonicated for $15 \mathrm{~min}$. A $1 \mathrm{~mL}$ aliquot of the upper phase was collected and transferred to a vial. The samples were analysed by HPLC coupled with an on-line fluorescence detector (RF-551; Shimadzu, Kyoto, Japan). A reverse phase C18 Kromasil column (pore size, $100 \AA$; $\mathrm{L} \times \mathrm{ID}, 250 \mathrm{~mm} \times 2.1 \mathrm{~mm}$; and particle size, $5 \mu \mathrm{m})$ was used to separate the tocopherols and tocotrienols. The mobile phase was composed of a methanol: water mix $(95: 5 \mathrm{v} / \mathrm{v})$. Tocopherols and tocotrienols were detected at $295 \mathrm{~nm}$ excitation and $330 \mathrm{~nm}$ emission wavelengths. The limits of detection were $2.5 \mu \mathrm{g} / \mathrm{mL}$ for $\alpha$-tocopherol, $1.25 \mu \mathrm{g} / \mathrm{mL}$ for $\gamma$-tocopherol, $0.3135 \mu \mathrm{g} / \mathrm{mL}$ for $\delta$-tocopherol, $0.1 \mu \mathrm{g} / \mathrm{mL}$ for $\alpha$-tocotrienol, and $0.3125 \mu \mathrm{g} / \mathrm{mL}$ for $\gamma$-tocotrienol. The peaks were identified using standards and quantified by calibration curves using their linear regression equations. The correlation coefficients $\left(R^{2}\right)$ of the standard curves were 0.9989 , $0.9996,0.9991,0.9972$, and 0.9992 for $\alpha$-tocopherol, $\gamma$-tocopherol, $\delta$-tocopherol, $\alpha$-tocotrienol, and $\gamma$-tocotrienol, respectively. The concentrations were confirmed spectrophotometrically based on the UV absorption profiles of pure tocols at their maximum wavelengths [13]. The results are expressed in $\mathrm{mg}$ of vitamin E/100 $\mathrm{g}$ berry seed oil.

2.8. Determination of Carotenoids by HPLC. Tert-butyl methyl ether (MTBE; $1 \mathrm{~mL}$ ) was added to $0.04 \pm 0.005 \mathrm{~g}$ of extracts and vortexed. The samples were transferred to amber vials and analysed by using HPLC equipped with a UV-visible photodiode array detector (996, Waters; Millipore, MA, USA). The carotenoids were separated using reverse-phase elution on a C30 column $(5 \mu \mathrm{m}, 250 \times 4.6 \mathrm{~mm}$ ID; YMC Europe GmbH, Schermbeck, Germany). The absorption spectrum from $250 \mathrm{~nm}$ to $550 \mathrm{~nm}$ was measured. The limits of detection were $62.2 \mu \mathrm{g} / \mathrm{mL}$ for $\beta$-carotene and $312.5 \mu \mathrm{g} / \mathrm{mL}$ for lutein. The mobile phase consisted of methanol and MTBE. The following gradient mixture was used for black currant and bilberry seed oils: isocratic elution with $85 \%(\mathrm{v} / \mathrm{v}) \mathrm{MeOH}$ and $15 \%(\mathrm{v} / \mathrm{v})$ MTBE for $2 \mathrm{~min}$; the gradient was then built up over 9 min with $75 \% \mathrm{MeOH}$ and 25\% MTBE; for the next $12 \mathrm{~min}$, the gradient attained 10\%
$\mathrm{MeOH}$ and 90\% MTBE; in the following 3 min, the gradient reached the initial composition of $85 \% \mathrm{MeOH}$ and $15 \%$ MTBE, followed by isocratic elution for the final $4 \mathrm{~min}$. For cloudberry seed oil, the gradient mixture was obtained as follows: the initial conditions of $85 \% \mathrm{MeOH}$ and $15 \% \mathrm{MTBE}$ were established over $6 \mathrm{~min}$ as $75 \% \mathrm{MeOH}$ and 25\% MTBE, progressing to $60 \% \mathrm{MeOH}$ and $40 \% \mathrm{MTBE}$ over $1 \mathrm{~min}$ and $10 \mathrm{MeOH}$ and $90 \% \mathrm{MTBE}$ for $16 \mathrm{~min}$, and the gradient was reset to the initial conditions over $3 \mathrm{~min}$ and equilibrated for an additional $6 \mathrm{~min}$. Lutein and $\beta$-carotene were identified on the basis of their retention times and the spectral characteristics of pure standards, as described by Svelander et al. [14]. Quantifications were made using the linear regression equations from standard curves. The $R^{2}$ was 0.9991 for $\beta$-carotene and 0.9999 for lutein, for the analysis of black currant and bilberry seed oils, and 0.9978 for $\beta$-carotene and 1 for lutein, for cloudberry seed oils. The concentration of the standard solutions was previously determined spectrophotometrically based on the UV absorption profiles of pure $\beta$-carotene and lutein at their maximum wavelengths [15]. The results are expressed in $\mathrm{mg}$ of carotenoids $/ 100 \mathrm{~g}$ of berry seed oil.

2.9. Free Radical-Scavenging Activity (DPPH Method). The antioxidant activities of the extracts were evaluated using the 1,1-diphenyl-2-picrylhydrazyl (DPPH) method, according to the procedure of Brand-Williams et al. [16]. All the solutions were prepared in ethanol. The samples were diluted to obtain five different concentrations, so as to determine the effective concentration $\left(\mathrm{EC}_{50}\right)$. An aliquot of $1 \mathrm{~mL}$ of each dilution was mixed with $1 \mathrm{~mL}$ of freshly prepared DPPH solution $(100 \mu \mathrm{M})$. Solutions of $\alpha$-tocopherol were used as the positive control [17]. The mixtures were incubated in the dark at room temperature. After $1 \mathrm{~h}$, the change in the absorbance after the reaction between radical scavengers and DPPH was measured at $517 \mathrm{~nm}$ in a spectrophotometer (Ultrospec 1000; Pharmacia Biotech (Biochrom) Ltd., Cambridge, England). The results were expressed in $\mathrm{mg}$ oil $/ \mathrm{mL}$ of ethanol.

2.10. Statistical Analysis. The analyses were carried out in triplicate. Statistical significance was tested by performing analysis of variance (ANOVA), followed by a Tukey post hoc test (level of significance of $p=0.05$ ). Correlation among $\mathrm{EC}_{50}$ and antioxidants (vitamin $\mathrm{E}$ and carotenoids) was calculated using Pearson's correlation coefficient $(r)$ (level of significance of $p=0.01$ ). The correlations were analysed for each antioxidant separately and for the sum of the $\mathrm{EC}_{50}(\mathrm{mg}$ antioxidant $/ \mathrm{mL}$ ethanol) and concentrations ( $\mathrm{mg}$ antioxidant/100 $\mathrm{g}$ oil) of vitamin $\mathrm{E}$ and carotenoids.

\section{Results and Discussion}

3.1. Light Microscopy Analysis of Berry Seed Particles. The extraction process involves two different extraction periods; the first period is characterised by the rapid extraction of surface and shallow subsurface oil, while the second period proceeds more slowly and is controlled by diffusion of the 
fluid into the matrix [11]. Figures $1(\mathrm{a})-1(\mathrm{c})$ show the LM images of the dry and ground seeds of cloudberry (a), black currant (b), and bilberry (c) before extraction. The pretreatments disrupted the seeds, revealing the interior part divided by the lamellar structure. The milling step broke several of the cells, releasing immediately some of the oil from the cells, which could be easily extracted. The oil droplets spread around the seed particles were dispersed from the particle surface by the addition of a water droplet to the objective glass. In Figure 1(a), the presence of a big oil droplet is shown (indicated by a white arrow). The milling step disrupted each berry seed in a different way, depending on the size of the seed and the cell shape. The seeds of cloudberry are larger and have higher density than the bilberry and black currant seeds [18]. Differences in the weights and sizes of seeds can produce heterogeneous particles after milling, with different shapes and sizes. The disrupted cells are indicated by arrows (black) in Figures 1(a)-(c). Cloudberry seeds have the largest cells of the three berry types, while bilberry seeds have the longest and narrowest cells (Figures 1(a) and 1(c)), which may have facilitated the extraction from the inner part of the broken bilberry seed cells. Black currant seeds (Figure 1(b)) have the smallest cells and particles. Longer milling times might break the cloudberry and bilberry seeds into smaller particles with larger surface areas, resulting in more efficient extractions. Further investigations into the effects of pretreatments of the investigated berries are necessary to optimise the extraction.

The small cells and seed particles present a larger membrane surface area, facilitating the extraction of nonpolar compounds from the membranes, for example, of the vitamin $E$ located in the cell membranes [19]. Milling of the seeds broke the cell membranes and released to the surface the oil than contains vitamin E. This may explain why a major fraction of the vitamin $\mathrm{E}$ was extracted during the first part of the extraction, which was followed by a decrease in the extraction rate due to mass transfer resistance from the cell membrane. As shown in Figures 1(a)-1(c), the particle cores have many intact cells, which may have decreased the extraction rates of other compounds present in the oil.

3.2. Extraction Yields. The yields and chemical compositions of the cloudberry, black currant, and bilberry seed oils were assessed after $\mathrm{SFE}$ at $50^{\circ} \mathrm{C}$ and $80^{\circ} \mathrm{C}$ or after hexane extraction (which was performed at room temperature and evaporated at $\left.40^{\circ} \mathrm{C}\right)$. Figure 2 presents the yield $\%(\mathrm{w} / \mathrm{w})$ values of the cloudberry, black currant, and bilberry seed oils. Significantly higher yields were obtained with hexane extraction compared to SFE. Studies comparing SFE and conventional extraction using hexane as solvent often report higher extraction yields with the conventional extraction method [20, 21]. However, since hexane is hazardous to workers and the environment, more gentle extraction procedures are needed [22]. In addition, a higher yield may not reflect the quality of the extracts. Johansson et al. [18] assessed the oil contents of berry seeds with moisture contents of $6 \%$, similar to the current work, using the Folch procedure, which is another conventional extraction method. They reported for cloudberry, black currant, and bilberry seeds oil content of $11.9 \%, 15.9 \%$, and $30.5 \%$, respectively. In the current work, lower oil levels were obtained with hexane extraction, which might be due to the differences in the type of cultivar, geographical origin, and the genotype [23]. The highest yields were obtained for bilberry seeds. Gustinelli et al. [24] have reported a higher extraction yield $(21.78 \%)$ for bilberry seed oil extracted at 350 bar and $50^{\circ} \mathrm{C}$. Since extraction time and flow rate are important parameters for SFE, the higher value seen in the present study might be explained by the longer extraction time $(80 \mathrm{~min})$ and higher flow rate $\left(40 \mathrm{~g} \mathrm{CO}_{2} / \mathrm{min}\right)$. The measured yields were $2.0 \%$ and $18.8 \%$ for black currant seeds extracted by SFE at $50^{\circ} \mathrm{C}$ and for bilberry seeds extracted by hexane, respectively. For SFE, the yields of cloudberry and black currant seed oils were higher at $80^{\circ} \mathrm{C}$ than at $50^{\circ} \mathrm{C}$. The temperature is considered to influence the yield of oil based on two counteracting forces [25]. At constant pressure, an increase in temperature decreases the solvent density, leading to a decrease in solubility. However, an increase in temperature increases the vapour pressure of the solutes, thereby improving the solubility of the oil during exposure to $\mathrm{SC}-\mathrm{CO}_{2}$. The effect of the increase in temperature depends on which one of the two forces is predominant. In the present study, the vapour pressure predominated during SFE of the black currant and cloudberry seeds at 350 bar. In mixtures of similar compounds, the intermolecular interactions are similar, and the vapour pressure depends on the molecular weights of the compounds [26]. However, in complex mixtures such as berry seed oils, complex intermolecular interactions result in significant differences compared with solubilities of the pure lipids (fatty acids and mono-, di-, and triacylglycerols) [27]. Therefore, the vapour pressure and its effects on the extraction yields of different berry seeds extracted under the same conditions are more difficult to predict.

3.3. Fatty Acid Composition. Table 1 shows the fatty acid compositions of cloudberry, black currant, and bilberry seed oils extracted by SFE at different temperatures and by hexane extraction. The major fatty acids were linoleic $(18: 2$ $n-6)$ and $\alpha$-linolenic acid (18:3n-3). Only the bilberry seed oil had $n-6 / n-3$ ratios $\leq 1$. The sum of the PUFAs ranged from $66.8 \%$ to $75.9 \%$ of the total fatty acids for bilberry seeds extracted by hexane and for black currant seeds extracted by SFE at $50^{\circ} \mathrm{C}$, respectively. There were small but significant differences in the fatty acid compositions of the oils obtained by either SFE or hexane extraction. The largest relative compositional difference measured was the concentration $\alpha$-linolenic acid $(18: 3$ $n-3)$, which was significantly lower in the black currant seed oils extracted by hexane. The $\alpha$-linolenic acid (18:3 $n-3)$ is mostly in the triacylglycerol fraction and therefore, its concentration relies on the solubility of the triacylglycerols, which depends on their molecular weights [28]. Johansson et al. [28] have reported 26 different triacylglycerol species for black currant seed oil. 


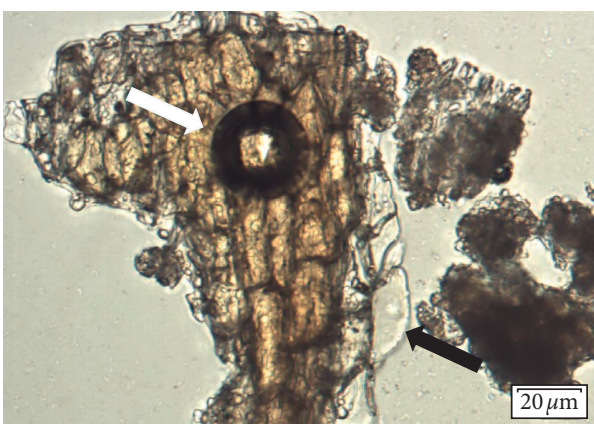

(a)

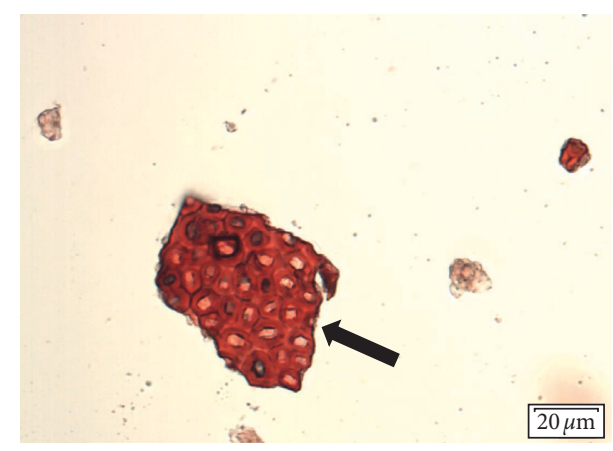

(b)

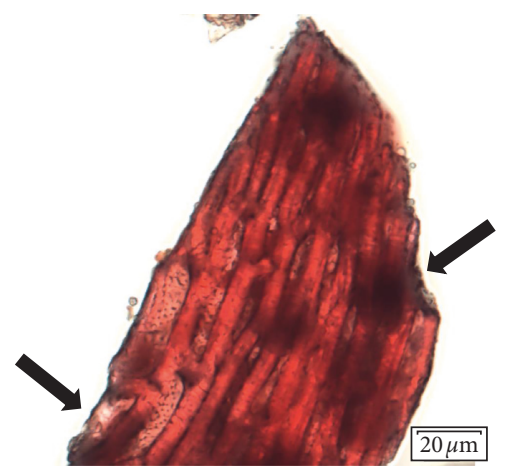

(c)

Figure 1: Seeds of cloudberry (a), black currant (b), and bilberry (c) dried and milled for $30 \mathrm{~s}$. White arrow indicates oil droplet released after milling. Black arrows indicate disrupted cells.

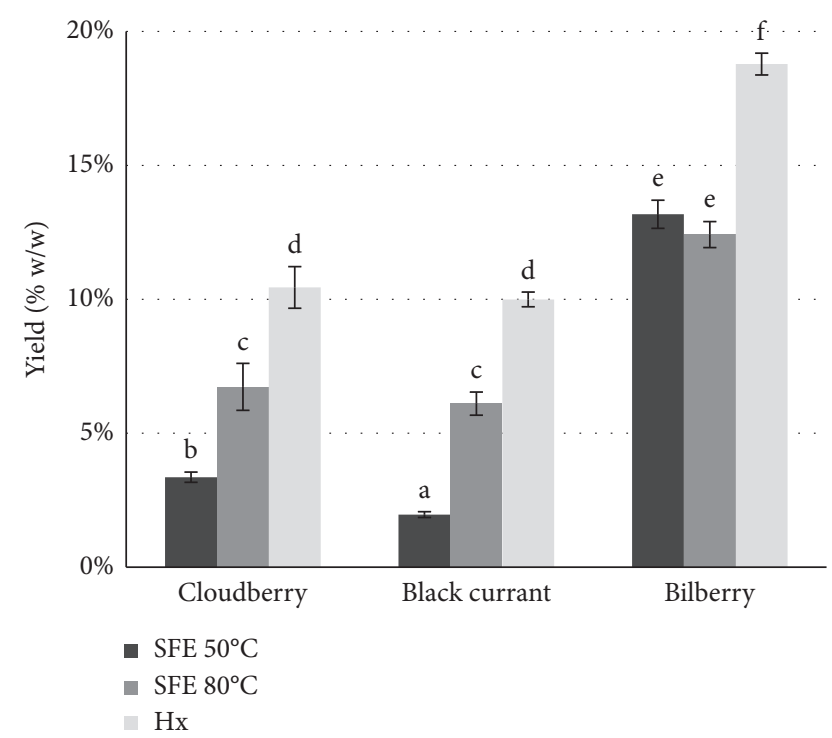

Figure 2: Extraction yield (\% w/w) of cloudberry, black currant, and bilberry seed oils extracted by SFE at different temperatures and by hexane extraction. Results are mean values \pm standard deviation of triplicate extractions. Different letters above error bars denote significant difference $(p<0.05)$ according to ANOVA followed by Tukey's post hoc test.

All the oils analysed had high percentages of PUFA and the major fatty acids were linoleic and $\alpha$-linolenic acid. Furthermore, the black currant seed oil had a high level of $\gamma$-linolenic acid $(18: 3 n-6)$ and was the only berry oil in which stearidonic acid $(18: 4 n-3)$ was detected. Both $\gamma$-linolenic and stearidonic acids are associated with reduced inflammation [29, 30]. Similar results for the fatty acid profile have been reported in previous studies of SFE of cloudberry, black currant, and bilberry seed oils $[4,24,31,32]$.

3.4. Recovery of Antioxidants and Antioxidant Activity. Table 2 lists the contents of tocopherols and tocotrienols in the berry seed oils. The major vitamin $\mathrm{E}$ isomers detected in the seed oils from cloudberry, black currant, and bilberry were $\gamma$-tocopherol, $\alpha$-tocopherol, and $\gamma$-tocotrienol, respectively. The highest concentration of vitamin $\mathrm{E}$ was obtained in black currant seed oil extracted by SFE at $50^{\circ} \mathrm{C}$, while bilberry seed oil extracted by hexane extraction had the lowest vitamin E content. For cloudberry seeds, hexane extraction resulted in the highest recovery of vitamin E. Increasing the temperature of SFE enhanced the extraction of vitamin E for cloudberry and bilberry seeds; although for black currant seeds, increasing the temperature was found to decrease the extraction yield. In general, the oils with lower yields contained higher concentrations of vitamin E. A strong negative correlation between the oil yield and the concentration of vitamin $\mathrm{E}$ was found $(r=-0.846$, $p=0.01$ ), which suggests that most of the vitamin E could be extracted. Vitamin $\mathrm{E}$ is soluble in triacylglycerols and can be easily extracted during SFE of seeds [25]. In plant seeds, the vitamin $\mathrm{E}$ is mostly located in the membranes [33]. The 


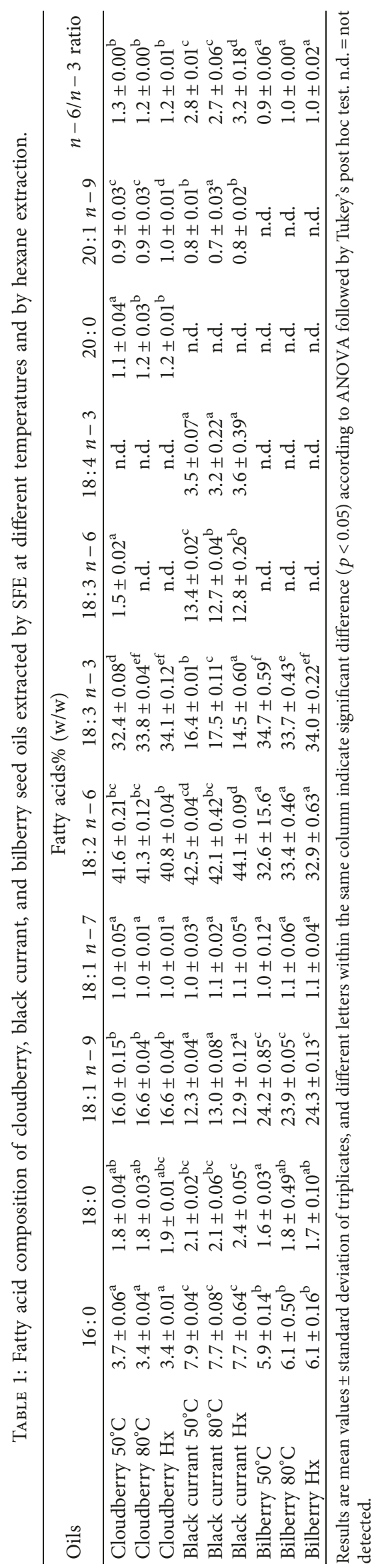


TABLE 2: Content of tocopherols (T) and tocotrienols (Tr) in cloudberry, black currant, and bilberry seed oils extracted by SFE at different temperatures and by hexane extraction.

\begin{tabular}{|c|c|c|c|c|c|c|c|}
\hline \multirow{2}{*}{ Oils } & \multicolumn{6}{|c|}{$\mathrm{mg} / 100 \mathrm{~g}$ oil } & \multirow{2}{*}{$\begin{array}{c}\mathrm{mg} / 100 \mathrm{~g} \text { dry } \\
\text { seeds } \\
\text { Total }\end{array}$} \\
\hline & $\alpha-\mathrm{T}$ & $\gamma-\mathrm{T}$ & $\delta$ - $\mathrm{T}$ & $\alpha-\operatorname{Tr}$ & $\gamma-\operatorname{Tr}$ & Total & \\
\hline Cloudberry $50^{\circ} \mathrm{C}$ & $38.2 \pm 1.44^{\mathrm{d}}$ & $67.1 \pm 2.95^{\mathrm{b}}$ & $4.9 \pm 0.01^{b}$ & n.d. & $0.8 \pm 0.03^{\mathrm{a}}$ & $111.0 \pm 5.38^{\mathrm{c}}$ & $3.7 \pm 0.18^{\mathrm{a}}$ \\
\hline Cloudberry $80^{\circ} \mathrm{C}$ & $40.2 \pm 1.34^{\mathrm{d}}$ & $74.9 \pm 1.91^{\mathrm{bc}}$ & $4.9 \pm 0.03^{b}$ & $0.2 \pm 0.00^{\mathrm{a}}$ & $1.1 \pm 0.01^{\mathrm{a}}$ & $121.3 \pm 4.67^{\mathrm{cd}}$ & $8.2 \pm 0.31^{\mathrm{c}}$ \\
\hline Cloudberry Hx & $40.3 \pm 0.13^{\mathrm{d}}$ & $84.6 \pm 1.53^{c}$ & $5.5 \pm 0.05^{\mathrm{b}}$ & n.d. & $1.0 \pm 0.06^{\mathrm{a}}$ & $131.5 \pm 2.37^{\mathrm{d}}$ & $13.7 \pm 0.25^{\mathrm{e}}$ \\
\hline Black currant $50^{\circ} \mathrm{C}$ & $122.1 \pm 1.24^{\mathrm{f}}$ & $102.7 \pm 6.10^{d}$ & $16.0 \pm 0.67^{\mathrm{d}}$ & $0.3 \pm 0.02^{\mathrm{b}}$ & $0.7 \pm 0.02^{\mathrm{a}}$ & $241.8 \pm 9.65^{\mathrm{f}}$ & $4.7 \pm 0.19^{\mathrm{b}}$ \\
\hline Black currant $80^{\circ} \mathrm{C}$ & $93.2 \pm 1.21^{\mathrm{e}}$ & $87.4 \pm 0.02^{\mathrm{c}}$ & $13.7 \pm 0.06^{\mathrm{c}}$ & $0.3 \pm 0.01^{b}$ & $2.4 \pm 0.01^{\mathrm{a}}$ & $197.0 \pm 1.58^{\mathrm{e}}$ & $12.0 \pm 0.09^{\mathrm{d}}$ \\
\hline Black currant $\mathrm{Hx}$ & $30.7 \pm 1.11^{\mathrm{c}}$ & $69.7 \pm 1.78^{\mathrm{b}}$ & $12.5 \pm 0.17^{\mathrm{c}}$ & n.d. & $0.1 \pm 0.02^{\mathrm{a}}$ & $113.0 \pm 4.34^{\mathrm{cd}}$ & $11.3 \pm 0.43^{\mathrm{d}}$ \\
\hline Bilberry $50^{\circ} \mathrm{C}$ & $18.1 \pm 0.12^{\mathrm{b}}$ & $3.6 \pm 0.17^{\mathrm{a}}$ & $0.3 \pm 0.01^{\mathrm{a}}$ & $0.6 \pm 0.00^{c}$ & $36.4 \pm 2.15^{\mathrm{c}}$ & $59.1 \pm 3.14^{\mathrm{b}}$ & $7.8 \pm 0.41^{\mathrm{c}}$ \\
\hline Bilberry $80^{\circ} \mathrm{C}$ & $25.8 \pm 0.32^{\mathrm{c}}$ & $4.8 \pm 0.00^{\mathrm{a}}$ & $0.5 \pm 0.01^{\mathrm{a}}$ & $0.7 \pm 0.01^{\mathrm{d}}$ & $37.4 \pm 1.84^{\mathrm{c}}$ & $69.3 \pm 3.06^{\mathrm{b}}$ & $8.6 \pm 0.38^{c}$ \\
\hline Bilberry Hx & $4.7 \pm 0.19^{\mathrm{a}}$ & $1.6 \pm 0.03^{\mathrm{a}}$ & $0.2 \pm 0.01^{\mathrm{a}}$ & n.d. & $10.7 \pm 0.39^{\mathrm{b}}$ & $17.2 \pm 0.85^{\mathrm{a}}$ & $3.2 \pm 0.16^{\mathrm{a}}$ \\
\hline
\end{tabular}

Results are mean values \pm standard deviation of triplicates, and different letters within the same column indicate significant difference $(p<0.05)$ according to ANOVA followed by Tukey's post hoc test; n.d. = not detected.

milling damages the cells in the membranes (Figure 3), which could facilitate the extraction of the vitamin $\mathrm{E}$ in the initial phase of extraction. Shen et al. have reported a higher extraction rate at the beginning of extraction of $\alpha$-tocopherol at similar pressure $(310 \mathrm{bar})$ and low temperature $\left(40^{\circ} \mathrm{C}\right)$ [34]. In the present work, oil samples with high yields had lower vitamin $\mathrm{E}$ concentrations because of a dilution effect from the other nonpolar compounds, such as mono-, di-, and tri-acylglycerols, which continued being recovered during the final part of the extraction.

Previous studies have reported the vitamin E concentrations for cloudberry, black currant, and bilberry seed oils extracted at $350 \mathrm{bar}$ and $50^{\circ} \mathrm{C}[4,24]$. Yang et al. [4] reported a higher concentration of vitamin $\mathrm{E}$ for cloudberry seed oil (260 mg/100 g oil) and lower concentrations for black currant and bilberry seed oils (110 and $40 \mathrm{mg} / 100 \mathrm{~g}$ oil, resp.). Gustinelli et al. [24] have reported a higher concentration of vitamin $\mathrm{E}$ for bilberry seed oil ( $62.5 \mathrm{mg} / 100 \mathrm{~g}$ oil). The longer extraction time used in both studies $(120 \mathrm{~min}$ and $80 \mathrm{~min}$ ) may have influenced the recovery rates of antioxidants. Moreover, variations in the chemical composition of the initial material could also have resulted in differences in the eventual extracts.

The use of SFE at 350 bar and $50^{\circ} \mathrm{C}$ for the extraction of black currant seed oil was advantageous for the recovery of $\alpha$-tocopherol (122 mg/100 g oil), whereas for bilberry seeds, extraction at $80^{\circ} \mathrm{C}$ was more efficient. Temperature is an important parameter for extraction, as it influences the solubility as well as the cellular matrix that contains the targeted compound. In plant matrices, the vitamin $\mathrm{E}$ is located in the cell membranes and forms complexes with lysophospholipids and free fatty acids [19]. As vitamin E is fat-soluble, it is concentrated in domains that are rich in lipids, thereby protecting the lipids from oxidation [35]. In plant seeds, the lipids (predominantly triacylglycerols) are also stored in organelles, called "oil bodies" [36]. When the seeds are dried and ground, the cell membranes and walls are broken and the oil bodies are easily accessed by the $\mathrm{SC}-\mathrm{CO}_{2}$ or the hexane, increasing their extractability.

Analyses of the levels of vitamin E in bilberry seed oil extracted by SFE (59 to $69 \mathrm{mg} / 100 \mathrm{~g}$ oil) and black currant

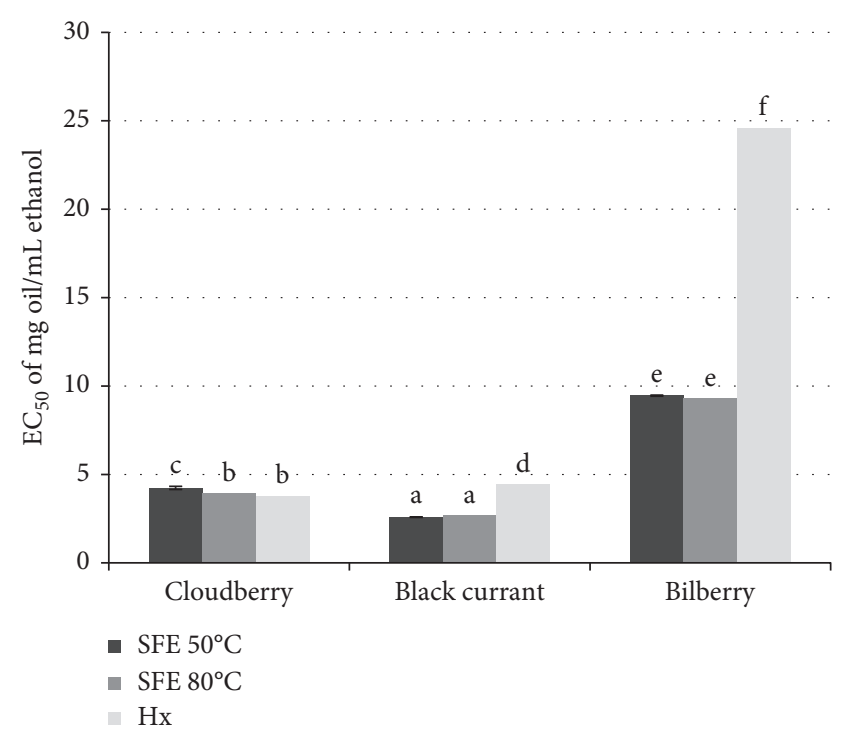

Figure 3: Values of $\mathrm{EC}_{50}$ of cloudberry, black currant, and bilberry seed oils extracted by SFE at different temperatures and by hexane extraction. Results are mean values \pm standard deviation of triplicates. Different letters above error bars denote significant difference $(p<0.05)$ according to ANOVA followed by Tukey's post hoc test.

seed oil extracted by SFE ( 242 to $113 \mathrm{mg} / 100 \mathrm{~g}$ oil) showed that the concentrations were higher than those reported in the literature for oils extracted with SFE (40 and $110 \mathrm{mg} / 100 \mathrm{~g}$ oil, resp.) [4]. In contrast, the concentration of vitamin $\mathrm{E}$ in cloudberry seed oil extracted by SFE (111 to $132 \mathrm{mg} / 100 \mathrm{~g}$ oil) was considerably lower than that described in the literature for cloudberry seed oils extracted by SFE (260 to $270 \mathrm{mg} / 100 \mathrm{~g}$ oil) $[4,9]$. The differences in the concentrations of vitamin E compared to other studies may reflect differences in extraction efficiency between the different extraction methods, differences in drying and milling of the seeds before extraction and environmental and physical factors, such as weather conditions, geographical region, ripeness, and berry variety, all of which are known to affect the chemical composition of the raw material $[37,38]$. 
TABLE 3: Content of carotenoids in cloudberry, black currant, and bilberry seed oils extracted by SFE at different temperatures and by hexane extraction.

\begin{tabular}{|c|c|c|c|c|c|}
\hline \multirow{2}{*}{ Oils } & \multicolumn{4}{|c|}{$\mathrm{mg} / 100 \mathrm{~g}$ oil } & \multirow{2}{*}{$\begin{array}{c}\mathrm{mg} / 100 \mathrm{~g} \text { seeds } \\
\text { Total }\end{array}$} \\
\hline & Lutein & $\beta$-carotene & Carotene equivalents & Total & \\
\hline Cloudberry $50^{\circ} \mathrm{C}$ & $0.9 \pm 0.00^{\mathrm{a}}$ & $4.3 \pm 0.10^{\mathrm{g}}$ & $31.3 \pm 0.09^{\mathrm{f}}$ & $36.5 \pm 0.18^{\mathrm{f}}$ & $1.2 \pm 0.01^{\mathrm{d}}$ \\
\hline Cloudberry $80^{\circ} \mathrm{C}$ & $0.2 \pm 0.00^{\mathrm{a}}$ & $2.6 \pm 0.03^{\mathrm{e}}$ & $34.9 \pm 0.14^{\mathrm{g}}$ & $37.7 \pm 0.16^{\mathrm{g}}$ & $2.5 \pm 0.01^{\mathrm{e}}$ \\
\hline Cloudberry $\mathrm{Hx}$ & n.d. & $3.4 \pm 0.04^{\mathrm{f}}$ & $53.5 \pm 0.09^{\mathrm{h}}$ & $57.0 \pm 0.06^{\mathrm{h}}$ & $5.9 \pm 0.01^{\mathrm{h}}$ \\
\hline Black currant $50^{\circ} \mathrm{C}$ & $12.1 \pm 0.02^{\mathrm{e}}$ & n.d. & $4.8 \pm 0.02^{\mathrm{b}}$ & $16.9 \pm 0.02^{\mathrm{e}}$ & $0.3 \pm 0.00^{\mathrm{a}}$ \\
\hline Black currant $80^{\circ} \mathrm{C}$ & $10.1 \pm 0.07^{\mathrm{d}}$ & $1.4 \pm 0.0^{\mathrm{d}}$ & $1.7 \pm 0.01^{\mathrm{d}}$ & $13.2 \pm 0.09^{c}$ & $0.8 \pm 0.01^{\mathrm{c}}$ \\
\hline Black currant $\mathrm{Hx}$ & $30.8 \pm 0.12^{\mathrm{f}}$ & $1.5 \pm 0.02^{\mathrm{d}}$ & $5.6 \pm 0.13^{\mathrm{e}}$ & $38.0 \pm 0.23^{\mathrm{g}}$ & $3.8 \pm 0.03^{\mathrm{g}}$ \\
\hline Bilberry $50^{\circ} \mathrm{C}$ & $2.4 \pm 0.01^{\mathrm{b}}$ & $0.1 \pm 0.00^{\mathrm{a}}$ & $0.4 \pm 0.00^{\mathrm{a}}$ & $2.8 \pm 0.02^{\mathrm{a}}$ & $0.4 \pm 0.00^{\mathrm{ab}}$ \\
\hline Bilberry $80^{\circ} \mathrm{C}$ & $3.2 \pm 0.03^{c}$ & $0.3 \pm 0.01^{\mathrm{b}}$ & $0.6 \pm 0.01^{\mathrm{a}}$ & $4.1 \pm 0.05^{\mathrm{b}}$ & $0.5 \pm 0.01^{b}$ \\
\hline Bilberry Hx & $12.1 \pm 0.56^{\mathrm{e}}$ & $0.9 \pm 0.03^{c}$ & $2.6 \pm 0.02^{c}$ & $15.6 \pm 0.57^{\mathrm{d}}$ & $2.9 \pm 0.13^{\mathrm{f}}$ \\
\hline
\end{tabular}

Results are mean values \pm standard deviation of triplicates, and different letters within the same column indicate significant difference $(p<0.05)$ according to ANOVA followed by Tukey's post hoc test; n.d. = not detected.

Cloudberry seed oil extracted by hexane gave the highest recovery of vitamin $\mathrm{E}$, when analysing the normalised data, expressed as $\mathrm{mg}$ of vitamin E/100 $\mathrm{g}$ of dry seeds (Table 2). The normalised data were derived by the vitamin $\mathrm{E}$ concentration ( $\mathrm{mg}$ vitamin $\mathrm{E} / 100 \mathrm{~g}$ oil) in relation to the extraction yield and represent the total amount of vitamin $\mathrm{E}$ extracted, independently of its final oil concentration. Black currant seed oil extracted by SFE at $50^{\circ} \mathrm{C}$, which had the highest recovery of vitamin $\mathrm{E}$ per oil, had a comparatively low normalised concentration. This indicates that at $80^{\circ} \mathrm{C}$ a higher level of vitamin $\mathrm{E}$ can be extracted from black currant seeds, although the high extraction yield under this condition exerts a dilution effect. The pure lipids belonging to the major lipid classes act as cosolvents during SFE and might influence the extraction of minor compounds, such as vitamin $\mathrm{E}$ and carotenoids [26].

Table 3 gives the concentrations of carotenoids in the berry seed oils. Lutein and $\beta$-carotene were identified in all the berry seed oils. Significantly higher recoveries (16 to $57 \mathrm{mg} / 100 \mathrm{~g}$ oil) of carotenoids were obtained by hexane extraction than by SFE for all three berry seeds. This was also the case when analysing the normalised data, expressed as $\mathrm{mg}$ of carotenoids/100 $\mathrm{g}$ of dry seeds. Lutein was the major carotenoid in the black currant and bilberry seed oils. The cloudberry seed oils had the highest concentrations of $\beta$-carotene and carotene equivalents, which contributed to the intense orange colour of the extracted oils. The concentrations of carotenoids were slightly lower than the value reported by Manninen et al. for the sum of $\alpha$-carotene and $\beta$-carotene in cloudberry seed oil extracted at 300 bar and $40^{\circ} \mathrm{C}$ [9]. Black currant seed oil extracted by hexane showed a high recovery of carotenoids, similar to that of the cloudberry seed oils extracted by SFE.

The $\mathrm{EC}_{50}$ value is the concentration at which an extract reduces the DPPH absorbance by $50 \%$. The lower the value is for an extract, the stronger is its antioxidant activity. As is evident from Figure 3, bilberry seed oils have the highest $\mathrm{EC}_{50}$ values, and thus, the lowest antioxidant activity compared with the oils extracted from cloudberry and black currant seeds. This is probably because of its low vitamin E and carotenoid contents. A significant negative correlation was found for the $\mathrm{EC}_{50}$ values and vitamin $\mathrm{E}$ content $(r=-0.763, p=0.01)$. The lowest $\mathrm{EC}_{50}$ values were obtained for black currant seed oils extracted by SFE (at $50^{\circ} \mathrm{C}$ and $80^{\circ} \mathrm{C}$ ), which also had the highest content of vitamin $\mathrm{E}$. The correlation of the $\mathrm{EC}_{50}$ values and carotenoid contents was also negative, albeit not statistically significant $(r=-0.377)$, indicating only a trend. This is probably explained by the fact that the antioxidant activities of carotenoids are not only restricted to scavenging activities, but these compounds also quench singlet oxygen [39]. However, when the values for vitamin $\mathrm{E}$ and carotenoids were combined, a higher negative correlation was found $(r=-0.802)$, indicating a synergistic effect between vitamin $\mathrm{E}$ and carotenoids. Carotenoids can transfer electrons to the $\alpha$-tocopheroxyl radical to regenerate tocopherol, which can then continue acting as an antioxidant [40]. A previous study has also reported a synergistic contribution of vitamin $\mathrm{E}$ and carotenoids to the antioxidant activities of lentils [23].

The reason for the variability of the extraction yields and recovery rates of antioxidants obtained for hexane extraction and for SFE at the two different temperatures may be related to differences in the structures and compositions of the three berry seeds. Therefore, the SFE conditions need to be optimised for each individual raw material. In addition, pretreatments (e.g., drying and milling) of the seeds should be taken into account. Milling seeds of different sizes and with different structural features lead to different particle sizes and surface areas for mass transfer, both of which influence the yield and composition of the oil.

\section{Conclusions}

This study investigated the yields, chemical compositions, and recovery rates of antioxidant compounds of seed oils extracted from cloudberries, bilberries, and black currants by solvent extraction and by SFE at 350 bar and at $50^{\circ} \mathrm{C}$ and $80^{\circ} \mathrm{C}$. Higher extraction yields were obtained with solvent extraction than SFE. The oils extracted from cloudberry, bilberry, and black currant seeds are excellent sources of PUFAs. Oils extracted by solvent extraction had better recovery of carotenoids than SFE while SFE showed higher vitamin $\mathrm{E}$ content and better antioxidant activity for black currant and bilberry seed oils. The lower $\mathrm{EC}_{50}$ of black currant seed oils is likely correlated to its high content of antioxidants. Black currant seed oils had the highest 
antioxidant activities, as seen by the low $\mathrm{EC}_{50}$ values and also their high concentrations of vitamin $\mathrm{E}$ and carotenoids. The results suggest that SFE extraction can be used as an efficient alternative to conventional extraction for concentration of tocopherols and carotenoids but due to the limited sample size, further studies are needed to support the findings. The seed cells differed in size and shape, and the milling step led to differences in the numbers of broken cells and particle sizes. These aspects warrant further investigation for optimisation of the pretreatments, so as to increase the total surface area of the cell wall particles and the number of broken cells.

\section{Data Availability}

The data (carotenoids, vitamin E, DPPH, and fatty acids) used to support the findings of this study are currently under embargo, while the research findings are commercialized. Requests for data (6 months), after publication of this article, will be considered by the corresponding author.

\section{Disclosure}

The results of this manuscript were partially presented at the 15th Euro Fed Lipid Congress at the European Federation of Food Science and Technology (EFFoST).

\section{Conflicts of Interest}

The authors declare no conflicts of interest.

\section{Acknowledgments}

The authors acknowledge the support provided by the Science without Borders Program (SwB 1229-13-3); CAPES Foundation; Ministry of Education of Brazil, Brasília, DF 70040-020, Brazil; ERA-Net; and SUSFOOD Project "Sustainable and healthy: development of sustainable processing technologies for converting by-products into healthy, added-value ingredients and food products."

\section{References}

[1] N. Pap, E. Pongrácz, M. Myllykoski, and R. Keiski, "Waste minimization and utilization in the food industry: processing of arctic berries, and extraction of valuable compounds from juice processing by-products," in Proceedings of the Waste Minimization and Resources Use Optimization Conference, pp. 159-168, Oulu, Finland, June 2004.

[2] D. Angin, "Utilization of activated carbon produced from fruit juice industry solid waste for the adsorption of Yellow 18 from aqueous solutions," Bioresource Technology, vol. 168, pp. 259-266, 2014.

[3] R. N. Cavalcanti, P. C. Veggi, and M. A. A. Meireles, "Supercritical fluid extraction with a modifier of antioxidant compounds from jabuticaba (Myrciaria cauliflora) byproducts: economic viability," in 11th International Congress on Engineering and Food, G. Saravacos, P. Taoukis, M. Krokida et al., Eds., pp. 1672-1678, Elsevier, New York, NY, USA, 2011.
[4] B. R. Yang, M. Ahotupa, P. Maatta, and H. Kallio, "Composition and antioxidative activities of supercritical $\mathrm{CO}_{2}$ extracted oils from seeds and soft parts of northern berries," Food Research International, vol. 44, no. 7, pp. 2009-2017, 2011.

[5] V. Van Hoed, I. Barbouche, N. De Clercq et al., "Influence of filtering of cold pressed berry seed oils on their antioxidant profile and quality characteristics," Food Chemistry, vol. 127, no. 4, pp. 1848-1855, 2011.

[6] F. Sahena, I. S. M. Zaidul, S. Jinap et al., "Application of supercritical $\mathrm{CO}_{2}$ in lipid extraction-a review," Journal of Food Engineering, vol. 95, no. 2, pp. 240-253, 2009.

[7] J. Azmir, I. S. M. Zaidul, M. M. Rahman et al., "Techniques for extraction of bioactive compounds from plant materials: a review," Journal of Food Engineering, vol. 117, no. 4, pp. 426-436, 2013.

[8] M. Bravi, F. Spinoglio, N. Verdone et al., "Improving the extraction of $\alpha$-tocopherol-enriched oil from grape seeds by supercritical $\mathrm{CO}_{2}$. Optimisation of the extraction conditions," Journal of Food Engineering, vol. 78, no. 2, pp. 488-493, 2007.

[9] P. Manninen, J. Pakarinen, and H. Kallio, "Large-scale supercritical carbon dioxide extraction and supercritical carbon dioxide countercurrent extraction of cloudberry seed oil," Journal of Agricultural and Food Chemistry, vol. 45, no. 7, pp. 2533-2538, 1997.

[10] C. P. Passos, M. A. Coimbra, F. A. Da Silva, and C. M. Silva, "Modelling the supercritical fluid extraction of edible oils and analysis of the effect of enzymatic pre-treatments of seed upon model parameters," Chemical Engineering Research and Design, vol. 89, no. 7, pp. 1118-1125, 2011.

[11] C. P. Passos, R. M. Silva, F. A. Da Silva, M. A. Coimbra, and C. M. Silva, "Enhancement of the supercritical fluid extraction of grape seed oil by using enzymatically pre-treated seed," Journal of Supercritical Fluids, vol. 48, no. 3, pp. 225-229, 2009.

[12] L. R. Cavonius, N. G. Carlsson, and I. Undeland, "Quantification of total fatty acids in microalgae: comparison of extraction and transesterification methods," Analytical and Bioanalytical Chemistry, vol. 406, no. 28, pp. 7313-7322, 2014.

[13] A. M. Lampi, "Analysis of tocopherols and tocotrienols by HPLC," in Selected Topics in the Analysis of Lipids, The AOCS Lipid Library, Urbana, IL, USA, 2011.

[14] C. A. Svelander, P. Lopez-Sanchez, P. D. A. Pudney, S. Schumm, and M. A. G. Alminger, "High pressure homogenization increases the in vitro bioaccessibility of $\alpha$ - and $\beta$-carotene in carrot emulsions but not of lycopene in tomato emulsions," Journal of Food Science, vol. 76, no. 9, pp. H215-H225, 2011.

[15] J. Val, J. Abadia, L. Heras, and E. Monge, "Higher-plant photosynthetic pigment analysis-determination of carotenoids and chlorophylls by HPLC," Journal of Micronutrient Analysis, vol. 2, pp. 305-312, 1986.

[16] W. Brand-Williams, M. E. Cuvelier, and C. Berset, "Use of a free-radical method to evaluate antioxidant activity," Food Science and Technology, vol. 28, no. 1, pp. 25-30, 1995.

[17] Z. H. Cheng, J. Moore, and L. L. Yu, "High-throughput relative DPPH radical scavenging capacity assay," Journal of Agricultural and Food Chemistry, vol. 54, no. 20, pp. 7429-7436, 2006.

[18] A. Johansson, P. Laakso, and H. Kallio, "Characterization of seed oils of wild, edible Finnish berries," Zeitschrift Fur Lebensmittel-Untersuchung und-Forschung A, vol. 204, no. 4, pp. 300-307, 1997. 
[19] J. Atkinson, R. F. Epand, and R. M. Epand, "Tocopherols and tocotrienols in membranes: a critical review," Free Radical Biology and Medicine, vol. 44, no. 5, pp. 739-764, 2008.

[20] X. Xu, Y. X. Gao, G. M. Liu, Q. Wang, and H. Zhao, "Optimization of supercritical carbon dioxide extraction of sea buckthorn (Hippophae thamnoides L.) oil using response surface methodology," LWT-Food Science and Technology, vol. 41, pp. 1223-1231, 2008.

[21] U. Salgin, S. Salgin, D. D. Ekici, and G. Uludag, "Oil recovery in rosehip seeds from food plant waste products using supercritical $\mathrm{CO}_{2}$ extraction," Journal of Supercritical Fluids, vol. 118, pp. 194-202, 2016.

[22] F. Temelli, "Perspectives on supercritical fluid processing of fats and oils," Journal of Supercritical Fluids, vol. 47, no. 3, pp. 583-590, 2009.

[23] B. Zhang, Z. Deng, Y. Tang et al., "Fatty acid, carotenoid and tocopherol compositions of 20 Canadian lentil cultivars and synergistic contribution to antioxidant activities," Food Chemistry, vol. 161, pp. 296-304, 2014.

[24] G. Gustinelli, L. Eliasson, C. Svelander, M. Alminger, and L. Ahrné, "Supercritical $\mathrm{CO}_{2}$ extraction of bilberry (Vaccinium myrtillus L.) seed oil: fatty acid composition and antioxidant activity," Journal of Supercritical Fluids, vol. 135, pp. 91-97, 2018.

[25] M. Mukhopadhyay, Natural Extract Using Supercritical Carbon Dioxide, CRC Press LLC, Boca Raton, FL, USA, 2000.

[26] O. Guclu-Ustundag and F. Temelli, "Correlating the solubility behavior of minor lipid components in supercritical carbon dioxide," Journal of Supercritical Fluids, vol. 31, no. 3, pp. 235-253, 2004.

[27] O. Guclu-Ustundag and F. Temelli, "Correlating the solubility behavior of fatty acids, mono-, di-, and triglycerides, and fatty acid esters in supercritical carbon dioxide," Industrial \& Engineering Chemistry Research, vol. 39, no. 12, pp. 47564766, 2000.

[28] A. Johansson, P. Laakso, and H. Kallio, "Molecular weight distribution of the triacylglycerols of berry seed oils analysed by negative-ion chemical ionization mass spectrometry," Zeitschrift Fur Lebensmittel-Untersuchung und-Forschung A, vol. 204, no. 4, pp. 308-315, 1997.

[29] S. Sergeant, E. Rahbar, and F. H. Chilton, "Gamma-linolenic acid, dihommo-gamma linolenic, eicosanoids and inflammatory processes," European Journal of Pharmacology, vol. 785, pp. 77-86, 2016.

[30] J. Whelan, "Dietary stearidonic acid is a long chain (n-3) polyunsaturated fatty acid with potential health benefits," Journal of Nutrition, vol. 139, no. 1, pp. 5-10, 2009.

[31] G. Gustinelli, L. Eliasson, C. Svelander, T. Andlid, L. Lundin, and L. Ahrne, "Supercritical fluid extraction of berry seeds: chemical composition, and antioxidant properties," in Science \& Technology Day-Poster Exhibition, p. 131, Chalmers University of Technology, Gothenburg, Sweden, 2017.

[32] G. Gustinelli, L. Eliasson, C. Svelander et al., "Supercritical fluid extraction of berry seeds: chemical composition, and antioxidant properties," in Proceedings of 15th Euro Fed Lipid Congress at the European Federation of Food Science and Technology (EFFoST), p. 488, Uppsala, Sweden, 2017.

[33] V. I. Lushchak and N. M. Semchuk, "Tocopherol biosynthesis: chemistry, regulation and effects of environmental factors," Acta Physiologiae Plantarum, vol. 34, no. 5, pp. 1607-1628, 2012.

[34] Z. Shen, M. V. Palmer, S. S. T. Ting, and R. J. Fairclough, "Pilot scale extraction of rice bran oil with dense carbon dioxide,"
Journal of Agricultural and Food Chemistry, vol. 44, no. 10, pp. 3033-3039, 1996.

[35] X. Y. Wang and P. J. Quinn, "The location and function of vitamin E in membranes (review)," Molecular Membrane Biology, vol. 17, no. 3, pp. 143-156, 2000.

[36] L. P. Zhao, Y. M. Chen, Y. J. Chen, X. Z. Kong, and Y. F. Hua, "Effects of $\mathrm{pH}$ on protein components of extracted oil bodies from diverse plant seeds and endogenous protease-induced oleosin hydrolysis," Food Chemistry, vol. 200, pp. 125-133, 2016.

[37] V. R. de Souza, P. A. P. Pereira, T. L. T. da Silva, L. C. D. Lima, R. Pio, and F. Queiroz, "Determination of the bioactive compounds, antioxidant activity and chemical composition of Brazilian blackberry, red raspberry, strawberry, blueberry and sweet cherry fruits," Food Chemistry, vol. 156, pp. 362-368, 2014.

[38] D. Helbig, V. Bohm, A. Wagner, R. Schubert, and G. Jahreis, "Berry seed press residues and their valuable ingredients with special regard to black currant seed press residues," Food Chemistry, vol. 111, no. 4, pp. 1043-1049, 2008.

[39] N. Mezzomo and S. R. S. Ferreira, "Carotenoids functionality, sources, and processing by supercritical technology: a review," Journal of Chemistry, vol. 2016, Article ID 3164312, 16 pages, 2016.

[40] D. H. Liu, J. Shi, A. C. Ibarra, Y. Kakuda, and S. J. Xue, “The scavenging capacity and synergistic effects of lycopene, vitamin $\mathrm{E}$, vitamin $\mathrm{C}$, and $\beta$-carotene mixtures on the DPPH free radical," LWT-Food Science and Technology, vol. 41, no. 7, pp. 1344-1349, 2008. 


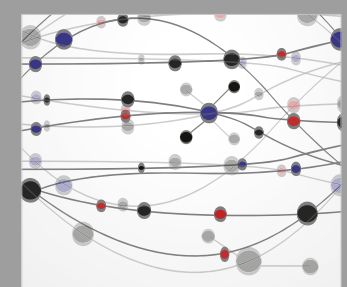

The Scientific World Journal
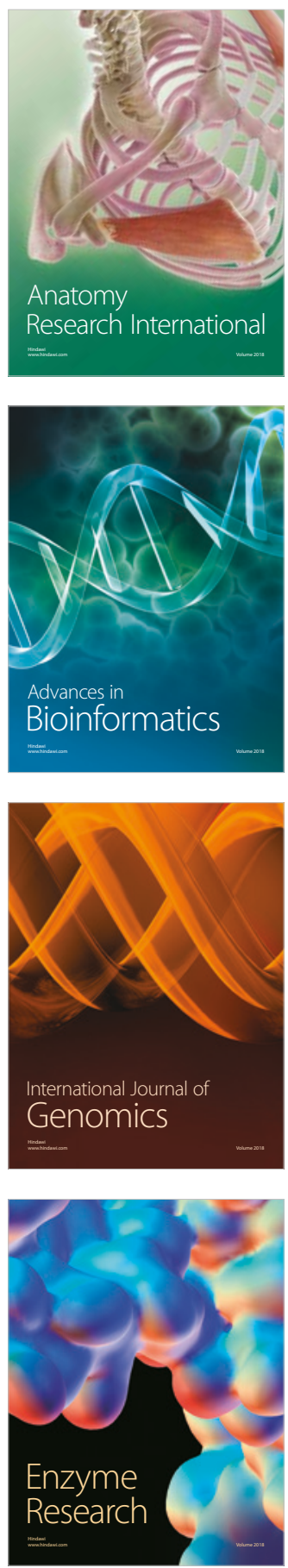
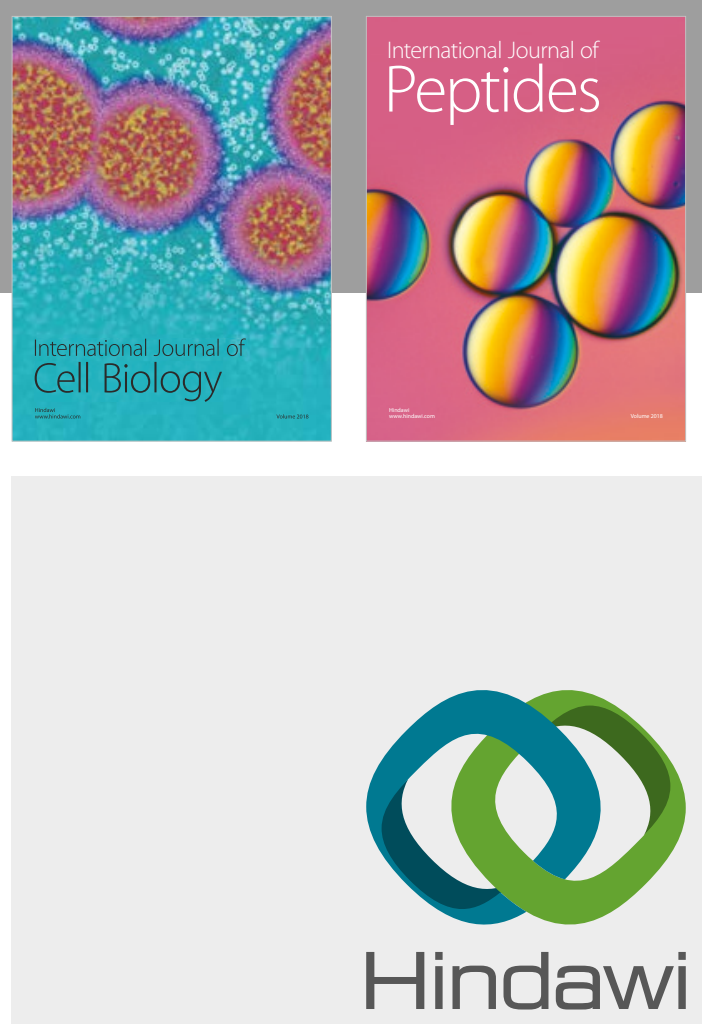

Submit your manuscripts at

www.hindawi.com
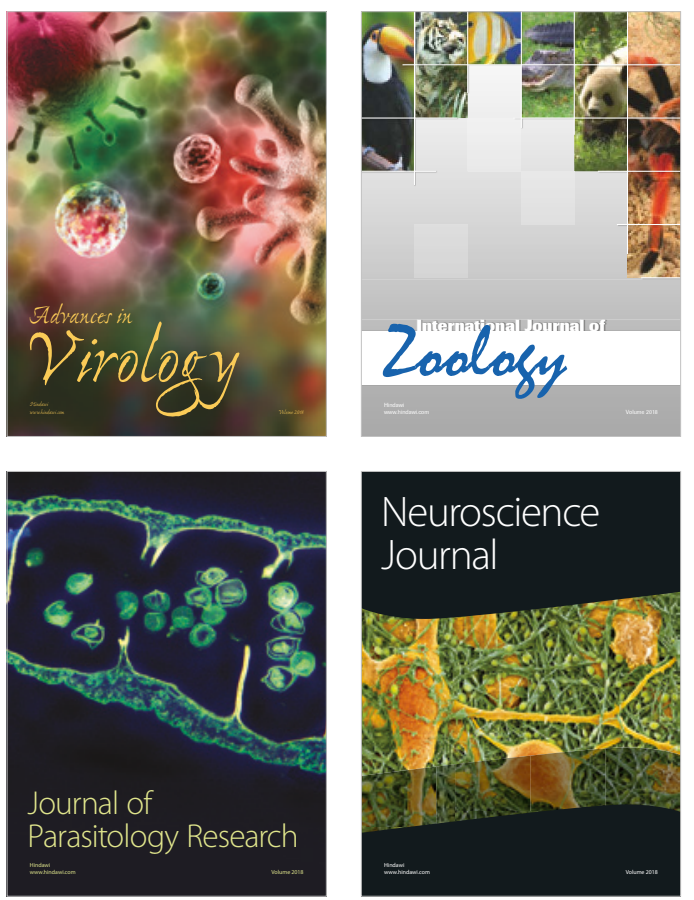
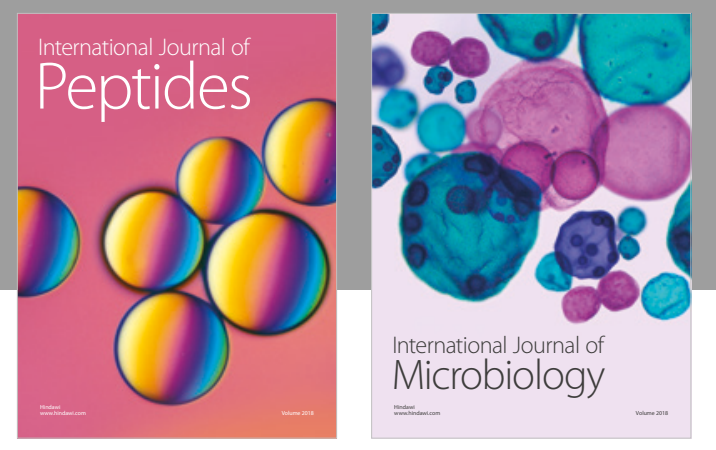

nternational Journal of Microbiology
Journal of
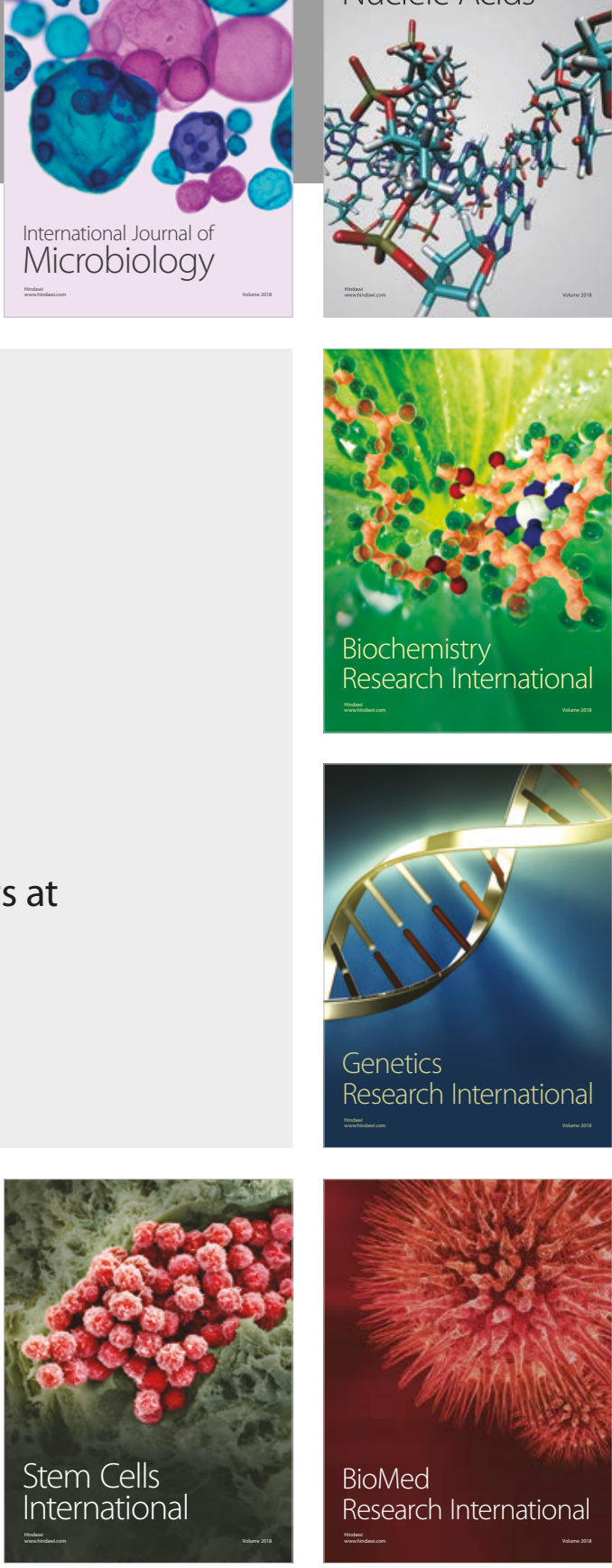
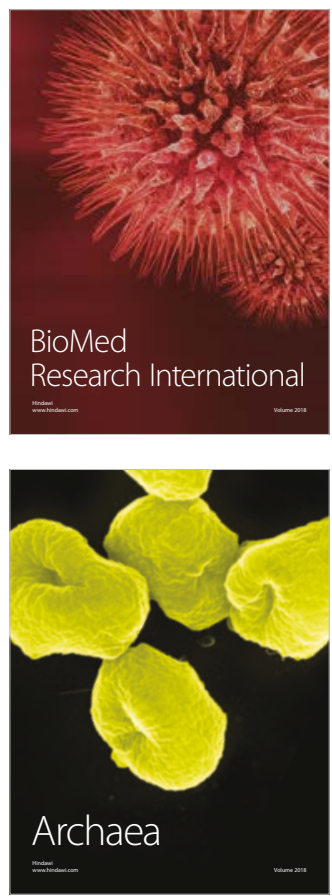